\title{
Leveraging human genetics to inform intervention strategies for multiple sclerosis
}

An Goris, PhD, and Bénédicte Dubois, MD, PhD

Neurology ${ }^{\circledR}$ 2019;92:735-736. doi:10.1212/WNL.0000000000007298

Striking changes in the demographic pattern of multiple sclerosis (MS), with increasing prevalence and incidence over time, especially in women, strongly indicate an influence of modifiable exposures on the disease. ${ }^{1}$ In understanding these important clues, it is difficult to pinpoint which of the many environmental, lifestyle, and sociodemographic changes that have occurred over the past decades such as higher smoking and obesity rates and earlier age at puberty are responsible. Genome-wide association studies (GWAS) have been highly successful in identifying genetic factors underlying many human traits, including $>200$ known genetic risk factors for MS. ${ }^{2}$ Environmental risk factors, including exposure to external or physiologic factors, have been much harder to pinpoint.

To establish an exposure-outcome relationship, randomized controlled trials (RCTs) are widely recognized as the best possible design, although they are often not feasible. Observational studies are prone to measurement error on exposure levels; to confounding, when an external factor distorts the relationship between the risk factor and the disease; and to reverse causation, when the disease precedes and causes changes in the risk factor. Our improved understanding of the genetic contribution to variation in human traits, including lifestyle-related traits, now provides an elegant genetic tool: mendelian randomization (MR). Through the Mendel laws, nature generates random genetic differences between individuals. This leads to a range of naturally occurring genetic predispositions for a risk factor, mimicking the biological effect of a modifiable exposure. MR correlates this genetic predisposition randomly assigned at conception with health outcomes later on in life, thereby greatly limiting confounding and reverse causation. Examples of MR demonstrate associations between genetically predisposed higher body mass index (BMI) and lower vitamin D levels with increased risk for MS. ${ }^{3-5}$

In the current issue of Neurology ${ }^{\circledR}$, Harroud et al. ${ }^{6}$ move ahead and apply MR to more complex aspects of disease causation. By leveraging genetic data from $>450,000$ individuals, they elegantly dissect highly correlated risk factors, in particular age at puberty and BMI. The genetic architecture of pubertal timing across both sexes is highly correlated. Age at puberty furthermore shares common regulatory mechanisms and shows a strong inverse genetic correlation with childhood and adult weight. GWAS have identified several hundred genetic variants rigorously associated with the exposure, i.e., age at puberty, BMI, or both. Harroud et al. use the combination of these variants as a genetic instrument to examine the exposure-outcome relationship in a large study population of 14,802 patients with MS and 26,703 controls. First, they establish that a 1-year-later genetically predicted age at puberty is associated with an $8 \%$ lower risk of MS. Subsequently, stratified analyses demonstrate that puberty-related variants not associated with BMI have no detectable influence on MS risk. On the other hand, the 30\% of pubertal timing-associated variants also associated with adult or childhood BMI reflect the positive correlation between BMI and MS. The same UK-Canadian teams previously estimated that a 1-SD or a 5-unit increase in genetically determined BMI, for example, from overweight $\left(\geq 25 \mathrm{~kg} / \mathrm{m}^{2}\right)$ to obese $\left(\geq 30 \mathrm{~kg} / \mathrm{m}^{2}\right)$, increases MS risk by $40 \%{ }^{3}$

MR critically relies on its own assumptions, and the authors went to great lengths to evaluate violations as detailed extensively. ${ }^{6}$ As limitations, the strong correlation between childhood and

\author{
Correspondence \\ Dr. Goris \\ an.goris@kuleuven.be
}

\section{RELATED ARTICLE}

Effect of age at puberty on risk of multiple sclerosis: A mendelian randomization study

Page 743

From the Department of Neurosciences (A.G., B.D.), Laboratory for Neuroimmunology, KU Leuven; Leuven Brain Institute (A.G., B.D.); and Department of Neurology (B.D.), University Hospitals Leuven, Belgium.

Go to Neurology.org/N for full disclosures. Funding information and disclosures deemed relevant by the authors, if any, are provided at the end of the editorial. 
adult BMI hampers the further exploration of age-specific effects, and the use of summary-level statistics precludes a sexspecific analysis of MS risk.

The current study attributes the inverse association between pubertal timing and MS essentially to BMI. It does not support a substantial role for effects of pubertal timing independent of weight status such as longer duration of exposure to sex hormones. BMI is associated with a broad range of biological, lifestyle, and sociodemographic aspects, shifting the BMI-MS question to the next, mechanistic level. Through MR, the same authors previously excluded 1 mechanistic hypothesis. They demonstrated that adiponectin, an anti-inflammatory cytokine negatively correlated with BMI, is not driving the risk of MS. ${ }^{7}$ Other alternative mechanisms include proinflammatory cytokines such as interleukin-6 that are positively associated with BMI. ${ }^{8}$ Studies on the genetic architecture of the immune system will provide appropriate genetic instruments for future use in MR.

Modifiable exposures lend themselves well to intervention, and MR is an elegant genetic tool to prioritize RCTs and to inform intervention strategies for improving public health. Extending the current MR approach to other autoimmune diseases would establish whether the influence of modifiable exposures is shared across these diseases, as is the case for shared genetic risk factors. ${ }^{2}$ If so, this would highlight the importance at the public health level of prevention strategies aiming at decreasing obesity rates, reducing not only the wellrecognized cardiovascular consequences but also rates of autoimmunity, affecting a substantial proportion of the population. In addition, it remains to be determined whether intervention after disease onset, when the patient comes to the attention of the neurologist, also has an effect. For many diseases, including MS, factors shaping the disease course after onset appear to be different from factors triggering disease, ${ }^{9}$ implying that dedicated studies are required to investigate factors underlying disease evolution. With the increasing availability of sufficiently large datasets of individuallevel genotypes and well-selected phenotypes and appropriate caution, MR is now starting to move beyond susceptibility toward heterogeneity. ${ }^{10}$ Future perspectives hence include investigating the effect of a modifiable exposure on phenotypes such as relapse rate and disease progression, offering clinical implications for prognosis and treatment.

\section{Study funding}

B.D. is a clinical fellow of the Research Foundation Flanders (FWO-Vlaanderen).

\section{Disclosure}

B.D. has received consulting fees and/or funding from Biogen Idec, Sanofi-Aventis, and Teva. B.D. and A.G. have received travel or consulting fees and/or research funding from Merck, Novartis, and Roche. Go to Neurology.org/N for full disclosures.

\section{References}

1. Koch-Henriksen N, Sorensen PS. The changing demographic pattern of multiple sclerosis epidemiology. Lancet Neurol 2010;9:520-532.

2. International Multiple Sclerosis Genetics Consortium. The Multiple Sclerosis Genomic Map: role of peripheral immune cells and resident microglia in susceptibility. bioRxi 2017. Available at: biorxiv.org/content/10.1101/143933v1. Accessed April 12, 2018.

3. Mokry LE, Ross S, Timpson NJ, Sawcer S, Davey Smith G, Richards JB. Obesity and multiple sclerosis: a mendelian randomization study. PLoS Med 2016;13:e1002053.

4. Mokry LE, Ross S, Ahmad OS, et al. Vitamin D and risk of multiple sclerosis: a mendelian randomization study. PLoS Med 2015;12:e1001866.

5. Gianfrancesco MA, Stridh P, Rhead B, et al. Evidence for a causal relationship between low vitamin D, high BMI, and pediatric-onset MS. Neurology 2017;88:1623-1629.

6. Harroud A, Morris JA, Forgetta V, et al. Effect of age at puberty on risk of multiple sclerosis: a mendelian randomization study. Neurology 2019;92:e1803-e1810.

7. Devorak J, Mokry LE, Morris JA, et al. Large differences in adiponectin levels have no clear effect on multiple sclerosis risk: a mendelian randomization study. Mult Scle 2017;23:1461-1468.

8. Carr EJ, Dooley J, Garcia-Perez JE, et al. The cellular composition of the human immune system is shaped by age and cohabitation. Nat Immunol 2016;17:461-468.

9. Hilven K, Patsopoulos NA, Dubois B, Goris A. Burden of risk variants correlates with phenotype of multiple sclerosis. Mult Scler 2015;21:1670-1680.

10. Paternoster L, Tilling K, Davey Smith G. Genetic epidemiology and mendelian randomization for informing disease therapeutics: conceptual and methodological challenges. PLoS Genet 2017;13:e1006944. 


\section{Neurology}

Leveraging human genetics to inform intervention strategies for multiple sclerosis An Goris and Bénédicte Dubois

Neurology 2019;92;735-736 Published Online before print March 20, 2019

DOI 10.1212/WNL.0000000000007298

This information is current as of March 20, 2019

Updated Information \&
Services

References

Subspecialty Collections

Permissions \& Licensing

Reprints including high resolution figures, can be found at: http://n.neurology.org/content/92/16/735.full

This article cites 9 articles, 1 of which you can access for free at: http://n.neurology.org/content/92/16/735.full\#ref-list-1

This article, along with others on similar topics, appears in the following collection(s):

All Genetics

http://n.neurology.org/cgi/collection/all_genetics

Association studies in genetics

http://n.neurology.org/cgi/collection/association_studies_in_genetics

Multiple sclerosis

http://n.neurology.org/cgi/collection/multiple_sclerosis

Risk factors in epidemiology

http://n.neurology.org/cgi/collection/risk_factors_in_epidemiology

Information about reproducing this article in parts (figures,tables) or in its entirety can be found online at:

http://www.neurology.org/about/about_the_journal\#permissions

Information about ordering reprints can be found online:

http://n.neurology.org/subscribers/advertise

Neurology ${ }^{\circledR}$ is the official journal of the American Academy of Neurology. Published continuously since 1951, it is now a weekly with 48 issues per year. Copyright () 2019 American Academy of Neurology. All rights reserved. Print ISSN: 0028-3878. Online ISSN: 1526-632X.

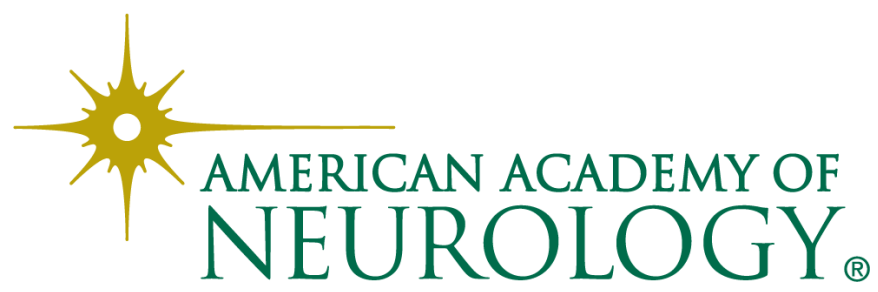

